\title{
PERFORMANCE OF PPTCT IN TERTIARY CARE CENTRE IN INDIA'S HIGHEST PREVALENCE STATE (MANIPUR)
}

\author{
Sumit Sukla Das ${ }^{1}$, L. Ranjit Singh ${ }^{2}$
}

${ }^{1}$ Resident Surgeon, Department of Obstetrics and Gynaecology, IGM Hospital, Agartala, Tripura.

2 Professor, Department of Obstetrics and Gynaecology, Regional Institute of Medical Sciences, Imphal, Manipur.

\begin{abstract}
\section{BACKGROUND}

Over two and a half decades have passed since the first diagnosis of AIDS in 1986, the prevalence of AIDS in adults has increased from $0.1 \%$ in 1990 to $0.3 \%$ in 2010 . A major implication of the rising trend of infection among women is mother-to-child transmission, which accounts $90 \%$ of paediatric infection. Manipur is the highest prevalent state for HIV infection in India (2010).

The objective of this study is to study the incidence of HIV among pregnant women and of PPTCT among women of Manipur.
\end{abstract}

\section{MATERIALS AND METHODS}

A retrospective study conducted in the Department of OBSGYN, where analysis of patients attending PPTCT Centre of RIMS in last 10 years (Jan 2003 - Aug 2013). All the pregnant women attending the antenatal clinic and those coming directly to the delivery room were counselled for HIV testing. Blood samples collected were possessed as per NACO guidelines.

\section{RESULTS}

Out of 136092 patients 103603 (76.12\%) patients were counselled, but 90522 (87.37\%) patients accepted the test, where 488 patients were found to be HIV positive with a prevalence of $0.53 \%$, of which $349(71.51 \%)$ delivered at RIMS and Nevirapine prophylaxis was given to 344 (98.56\%) patients to both mother and child. Only 34 mothers were allowed breast feeding and the remaining had replacement feeding.

\section{CONCLUSION}

To achieve a high success rate, PPTCT programmes must have well trained supportive staff who will take care of patients with great confidentiality. They must be backed up by effective HIV testing and counselling programmes and by good quality HIV/AIDS education.

\section{KEYWORDS}

PPTCT, Retrospective, Nevirapine.

HOW TO CITE THIS ARTICLE: Das SS, Singh LR. Performance of PPTCT in tertiary care centre in India's highest prevalence State (Manipur). J. Evolution Med. Dent. Sci. 2016;5(103):7527-7530, DOI: 10.14260/jemds/2016/1704

\section{BACKGROUND}

The history of HIV and AIDS is a short one. As recently as the 1970s, no one was aware of this deadly illness. Since then the global HIV/AIDS epidemic has become one of the greatest threats to human health and development. There is still no cure for HIV, but HIV treatment has improved enormously since the mid-1990s. HIV statistics for the end of 2011 indicate that around 34 million people are living with HIV, the virus that causes AIDS. Each year around 2.5 million more people become infected with HIV and 1.7 million die of AIDS. The worst affected region is Sub-Saharan Africa, wherein a few countries more than one in five adults is infected with HIV.

The adult HIV prevalence in India is 0.27 percent, as of 2011. ${ }^{1}$ There are still around 2.1 million people living with HIV in India.

Financial or Other, Competing Interest: None.

Submission 04-12-2016, Peer Review 17-12-2016,

Acceptance 19-12-2016, Published 26-12-2016.

Corresponding Author:

Dr. Sumit Sukla Das,

Type 4/35 Qtr. No.

Rabindrapalli Quarter Complex,

Paradise Chowmuhani.

E-mail: sumit_sdas@rediffmail.com

DOI: $10.14260 /$ jemds/2016/1704
Overall, India's HIV epidemic is slowing down with a 57 percent decline in new infections between 2000 and 2011, and a 29 percent decline in AIDS-related deaths between 2007 and 2011. The four states with the highest number of people living with HIV (Andhra Pradesh, Karnataka, Maharashtra and Tamil Nadu) are all in the South, and account for 53 percent of all HIV infections in India. Despite this, the adult HIV prevalence is falling in these high prevalence states. However, in a few states in the North and Northeast, HIV infections are rising.

Of all people living with HIV in India, 39 percent are women and 7 percent are children. A major implication of the rising trend of HIV infection in women is increasing the chance of Mother-To-Child Transmission (MTCT), which accounts for $90 \%$ of the paediatric infection. MTCT accounts for more than $10 \%$ of all new HIV infections globally. In an attempt to give the world an HIV-free generation, the programme of Prevention of Parent-To-Child Transmission (PPTCT) has been taken up, which aims at preventing the transmission of HIV infection from mother to child during antenatal, intranatal as well as postnatal period by various measures. With all the measures taken, the rate of MTCT can be brought down from $15 \%-30 \%$ to $2 \%{ }^{2}$

Manipur is one of the highest prevalence states in India with HIV prevalence rate among pregnant women attending ANC being $1.4 \%$. Manipur with hardly $0.2 \%$ population of India is contributing nearly $8 \%$ of India's total HIV positive cases. 
In 1998, Manipur AIDS Control Society (MACS) was formed. MACS in 2002 launched a pilot PPTCT project at the Jawahar Nehru Hospital and started in RIMS in 2003.

This paper analyse the performance of PPTCT in tertiary care centre (RIMS) in Imphal, Manipur from 2003 - August 2013.

\section{MATERIALS AND METHODS}

This is a retrospective study, which was conducted in the Department of Obstetrics and Gynaecology, Regional Institute of Medical Sciences, Imphal from 2003 to August 2013, a period of 11 years since the establishment of PPTCT centre in our institution. All the pregnant women attending the antenatal clinic for consultation and those coming directly to labour room for delivery (unbooked cases) were counselled for HIV testing, informed consent was taken and blood samples collected for HIV testing. Samples were processed as per NACO guidelines. The first test was done by CombAids-RS (Span Diagnostics Ltd.). If the sample tested was positive, then it was tested with HIV EIA Comb (J. Mitra and Co. Pvt. Ltd.). If the sample tested was positive in the second test, then the third test was done by SD Bioline (Standard Diagnostics, Inc.). The samples which tested positive with all the above tests were considered to be HIV positive (WHO strategy III). Seropositive women were questioned regarding their awareness of AIDS, personal habits, blood transfusion, drug abuse and method of contraception. Spouse of the seropositive pregnant women were also counselled and tested for HIV antibodies as above after taking written consent. Post-test counselling was done by the same post-test counsellor who did the pretest counselling and after maintaining strict confidentiality the reports were disclosed.

All women were counselled regarding mode of delivery and the role of elective LSCS. The women who gave consent for LSCS was taken up for the same along with women with obstetric indications for LSCS. Women those who did not give consent were only delivered vaginally along with women attending labour wards after onset of labour.

Nevirapine $200 \mathrm{mg}$ single dose was given to all mothers except in cases of IUFD and the patients already on Highly Active Antiretroviral Therapy (HAART), 4 hrs. before Elective LSCS and at the onset of labour for those who delivered vaginally. Nevirapine suspension $2 \mathrm{mg} / \mathrm{kg}$ was given to all the live babies.

Patients were counselled regarding mode of feeding for the babies along with pros and cons of breast feeding. Depending upon socioeconomic status and social practices feeding way was decided. Patients were regularly followed for complications and foetomaternal outcome. All the babies were referred to paediatric clinic for followup.

\section{RESULTS}

\begin{tabular}{|c|c|c|c|}
\hline Year & $\begin{array}{c}\text { No. of ANC } \\
\text { Registered }\end{array}$ & $\begin{array}{c}\text { No. of ANC } \\
\text { Counselled }\end{array}$ & $\begin{array}{c}\text { No. of ANC } \\
\text { Tested }\end{array}$ \\
\hline 2003 & 9860 & 4369 & 513 \\
\hline 2004 & 13703 & 3163 & 724 \\
\hline 2005 & 13804 & 8119 & 3169 \\
\hline 2006 & 13181 & 11300 & 10763 \\
\hline 2007 & 14382 & 12547 & 11848 \\
\hline 2008 & 17053 & 12540 & 10943 \\
\hline 2009 & 13425 & 11264 & 11261 \\
\hline 2010 & 11438 & 11438 & 11438 \\
\hline 2011 & 11620 & 11620 & 11620 \\
\hline 2012 & 10552 & 10169 & 10169 \\
\hline 2013 & 7074 & 7074 & 7074 \\
\hline Total & 136092 & $\mathbf{1 0 3 6 0 3}$ & $\mathbf{8 9 5 2 2}$ \\
\hline \multicolumn{4}{|c|}{ Table 1. Registration, Counselling } \\
& and Testing of Antenatal Mothers \\
\hline
\end{tabular}

\begin{tabular}{|c|c|c|c|c|c|}
\hline Years & $\begin{array}{l}\text { No. of HIV } \\
\text { Positive }\end{array}$ & $\begin{array}{l}\text { No. of HIV Positive } \\
\text { Delivered }\end{array}$ & $\begin{array}{l}\text { Mode of Delivery } \\
\text { (LSCS) }\end{array}$ & $\begin{array}{l}\text { No. of M \& B } \\
\text { NVP Given }\end{array}$ & $\begin{array}{c}\text { No. of Babies } \\
\text { Breast Fed }\end{array}$ \\
\hline 2003 & 8 & 6 & 0 & 6 & 5 \\
\hline 2004 & 23 & 13 & 5 & 13 & 2 \\
\hline 2005 & 44 & 29 & 14 & 29 & 5 \\
\hline 2006 & 96 & 54 & 16 & 50 & 1 \\
\hline 2007 & 105 & 53 & 18 & 53 & 6 \\
\hline 2008 & 54 & 38 & 8 & 38 & 5 \\
\hline 2009 & 43 & 42 & 16 & 41 & 2 \\
\hline 2010 & 34 & 29 & 7 & 29 & 0 \\
\hline 2011 & 35 & 30 & 9 & 30 & 1 \\
\hline 2012 & 28 & 37 & 10 & 37 & 4 \\
\hline 2013 & 18 & 18 & 1 & 18 & 3 \\
\hline Total & 488 & 349 & 104 & 344 & 34 \\
\hline
\end{tabular}

As evident from Table 1, total number of ANC registered from 2003 to August 2013 was 136092. Out of total ANC registered, 103603 underwent counselling and 90522 accepted the test. In the initial years, acceptance was low as in 2003 only $11.74 \%$, but now in last 4 years it is around $100 \%$. In spite of our whole hearted approach, it was not possible to counsel all the antenatal women as counselling could not be done on Sundays and Govt. holidays and the women who were admitted on Saturday after 2 P.M. and delivered normally by Sunday were discharged before Monday morning.

As per Table 2, number of women came out to be positive in the last 11 years was $488(0.53 \%)$ with maximum in the year 2007 , i.e. 105 patients and after that positivity rate was coming down in following years. Out of all women tested positive, only $349(71.51 \%)$ delivered in our institution. Mode of delivery was mostly vaginal delivery $(70.20 \%)$, except in patients with 
obstetric indications for LSCS and some of the patients who opted for elective LSCS. Nevirapine prophylaxis was given to 344 (98.56\%) HIV positive mothers delivered in our institution; 3 patients with Intrauterine Foetal Death (IUFD) and 2 patients already on Highly Active Antiretroviral Therapy (HAART) was not given nevirapine. All live born babies were given nevirapine suspension ( $2 \mathrm{mg} / \mathrm{kg}$ ). Out of 344 babies delivered to HIV positive women, only 34 babies was breast fed and rest was given artificial feeds.

Attempts was made to check the status of spouse of HIV positive women. Total number of spouse counselled was 252, but only 188 accepted the test. Out of 188, 145 (77.12\%) turned out to be positive.

Table 3 shows that most of HIV positive patients, i.e. $51.85 \%$ belong to 20 - 29 years of age which is most reproductive age group.

Table 4 and 5 delineates that primi gravida was the most affected group (48.37\%) as compared to multigravida and most of them staying in rural areas $(61.47 \%)$.

Table 6 and 7 shows that highest percentage of the patients $(61.07 \%)$ and their spouse (55.74\%) belong to unemployed group.

\begin{tabular}{|c|c|c|}
\hline Age in Years & Number & Percentage \\
\hline $15-19$ & 26 & $5.32 \%$ \\
\hline $20-29$ & 253 & $51.85 \%$ \\
\hline $30-39$ & 198 & $40.58 \%$ \\
\hline 40 and Above & 11 & $2.25 \%$ \\
\hline Total & 488 & $100 \%$ \\
\hline \multicolumn{3}{|c|}{ Table 3. Age Distribution of HIV Positive Patients } \\
\hline
\end{tabular}

\begin{tabular}{|c|c|c|}
\hline Parity & Number & Percentage \\
\hline P0 & 236 & $48.37 \%$ \\
\hline P1 & 129 & $26.44 \%$ \\
\hline P2 & 61 & $12.5 \%$ \\
\hline P3 & 24 & $4.91 \%$ \\
\hline P5 and Above & 15 & $3.07 \%$ \\
\hline Total & 23 & $4.71 \%$ \\
\hline \multicolumn{2}{|c|}{ Table 4. Parity Wise Distribution of Patients } \\
\hline
\end{tabular}

\begin{tabular}{|c|c|c|}
\hline Address & Number & Percentage \\
\hline Rural & 300 & $61.47 \%$ \\
\hline Urban & 188 & $38.53 \%$ \\
\hline Total & $\mathbf{4 8 8}$ & $\mathbf{1 0 0} \%$ \\
\hline \multicolumn{2}{|c|}{ Table 5. Address Wise Distribution } \\
\hline
\end{tabular}

\begin{tabular}{|c|c|c|}
\hline Occupation & Number & Percentage \\
\hline Housewife & 298 & $61.07 \%$ \\
\hline Govt. Employee & 20 & $4.10 \%$ \\
\hline Private & 71 & $14.55 \%$ \\
\hline Daily Wages & 99 & $20.28 \%$ \\
\hline Total & 488 & $100 \%$ \\
\hline \multicolumn{3}{|c|}{ Table 6. Occupation Wise Distribution } \\
\hline
\end{tabular}

\begin{tabular}{|c|c|c|}
\hline Occupation & Number & Percentage \\
\hline Unemployed & 272 & $55.74 \%$ \\
\hline Govt. Employee & 26 & $5.33 \%$ \\
\hline Private & 149 & $30.53 \%$ \\
\hline Daily Wages & 41 & $8.40 \%$ \\
\hline Total & $\mathbf{4 8 8}$ & $\mathbf{1 0 0 \%}$ \\
\hline Table 7. Husband's Occupation Wise Distribution \\
\hline
\end{tabular}

\section{DISCUSSION}

HIV is a deadly illness and still there is no cure for HIV, but HIV treatment has improved enormously since the mid-1990s. WHO promotes a comprehensive strategic approach for the prevention of HIV infection in infants and young children, consisting of four components ${ }^{3}$ : (1) Primary prevention of HIV infection; (2) Prevention of unintended pregnancies among women living with HIV; (3) Prevention of HIV transmission from mothers living with HIV to their infants; (4) Care, treatment and support for mothers living with HIV, their children and families.

A major implication of the rising trend of HIV infection in women is increasing the chance of Mother-To-Child Transmission (MTCT), which accounts for $90 \%$ of the paediatric infection. MTCT accounts for more than $10 \%$ of all new HIV infections globally. Therefore, treatment is required to prevent the same, which can be achieved through the use of Antiretroviral (ARV) drugs in pregnancy, choosing safer interventions of delivery, neonatal ART and safer feeding practices.

Women who have reached the advanced stages of HIV disease require a combination of ARV for their own health. This treatment, which must be taken every day for the rest of a woman's life is also highly effective at reducing the risk of mother-to-child transmission. Pregnant women who do not yet need treatment for their own HIV infection can take a short course of drugs to help protect their unborn babies.

The simplest of all PPTCT drug regimens was tested in the HIVNET 012 trial, which took place in Uganda between 1997 and 1999.4 This study found that a single dose of Nevirapine given to the mother at the onset of labour and to the baby after delivery roughly halved the rate of HIV transmission. As it is given only once to the mother and baby, single dose Nevirapine is relatively cheap and easy to administer. Since 2000 , thousands of babies in resource-poor countries have benefited from this simple intervention, which has been the mainstay of many PMTCT programmes. Colvin et $\mathrm{al}^{5}$ in their study in South Africa showed that rates of early transmission of HIV in an operational setting using single-dose nevirapine administered both to mother and child are similar to those obtained in clinical trials. Moodley et al $^{6}$ also confirmed in their study the safety and efficacy of short course ARV regimens in reducing MTCT in developing countries.

Present study indicates that as the years are passing, PPTCT services are improving in Manipur and also more and more patients are ready to undergo testing after proper counselling. Seroprevalence in 2003 in RIMS was 1.55\%, which comes down to $0.25 \%$ in 2013. This shows that prevalence of HIV infection is declining, but still we have to continue as well as expand the services to decrease the rate further and to prevent any new infection. If we fail the country may face the consequences that is faced by South Africa today, where one out of four pregnant women is infected with HIV.

As India is still a country with limited resources, single dose NVP both to mother and baby is still widely used to prevent MTCT and LSCS is not a major mode of delivery. Present study shows that coverage with single dose nevirapine therapy in our institution is around $98.56 \%$ in both mothers and newborns and only $29.8 \%$ of HIV positive patients underwent LSCS and that too mostly because of the obstetric indications. 
During postpartum period, an HIV infected woman should receive ongoing HIV related medical care including immune function monitoring, recommended therapy and prophylaxis for and treatment of opportunistic infections and other HIV related conditions. HIV infected women should receive gynaecologic care including regular Pap smears, reproductive counselling, information on how to prevent sexual and drug related transmission of HIV and treatment of gynaecologic conditions. HIV infected women should be informed of the importance of followup of children. Children whose HIV status is unknown require early diagnostic testing and prophylactic therapy to prevent Pneumocystis carinii pneumonia pending determination of their status. Uninfected children who are exposed to antiretroviral therapy should be assessed for potential short-term and long-term side effect.

In light of the high mortality in all children of HIV-infected women, programs for prevention of MTCT should be monitored not only in terms of HIV transmission avoided, but also in terms of child survival. ${ }^{7}$

Global 2015 targets of WHO was to reduce number of new HIV infections among children by $90 \%$ and decrease HIV associated deaths to women during pregnancy, delivery or puerperium by $50 \%$, decrease under 5 deaths due to HIV by at least $50 \%$ and provide antiretroviral therapy to all children with HIV and decrease MTCT rates less than 5\%. Over past decade, many low and middle income countries have achieved at least $80 \%$ coverage of services to prevent HIV transmission to babies, but still in country like India where resources are limited old interventions are used for PMTCT. We have studied that just by improving ANC coverage, counselling and old intervention drugs and techniques we can decrease MTCT rate, but for reaching towards the targets of 2015 we have to phase out it as a matter of priority in accordance with recent WHO guidelines. It will also leverage broader efforts to improve maternal and child health, the technical expertise of other countries, the aid effectiveness agenda, renewed engagement of regional bodies as well as development in research policies for focused and simplified treatment and interventions.

\section{CONCLUSION}

To achieve a high success rate, PPTCT programmes must have well trained, supportive staff who will take care of patients with great confidentiality. They must be backed up by effective HIV testing and counselling programmes and by good quality HIV/AIDS education.

\section{REFERENCES}

1. http://www.avert.org/hiv-aids-india.htm. NACO 2013. 'India: Annual Report 2012-13'.

2. http://www.avert.org/hiv-aids-india.htm. NACO (2013) 'India: Annual Report 2012-13'.

3. WHO. Antiretroviral drugs for Treating pregnant women and Preventing HIV infection in infants: towards universal access recommendations for a public health approach. World Health Organization, Geneva: WHO Press 2006.

4. Nevirapine for the prevention of mother to child transmission of HIV. WHO reconfirms its support for the use of nevirapine to prevent mother-to child transmission of HIV: World Health Organization, Geneva: WHO Press. 2001. http://www.niaid.nih.gov/daids/Prevention.htm.

5. Colvin M, Chopra M, Doherty $\mathrm{T}$, et al. Operational effectiveness of single-dose nevirapine in preventing mother-to-child transmission of HIV. Bull World Health Organ 2007;85(6):466-73.

6. Moodley D, Moodley J, Coovadia H, et al. A multicenter randomized controlled trial of nevirapine versus a combination of zidovudine and lamivudine to reduce intrapartum and early postpartum mother-to-child transmission of human immunodeficiency virus type 1 . J Infect Dis 2003;187(54):725-35.

7. Newell ML. Current issues in the prevention of mother-tochild transmission of HIV-1 infection. Trans R Soc Trop Med Hyg 2006;100(1):1-5. 